\title{
El fre magnètic: experimentant amb els corrents de Foucault
}

Francesc Martínez Espinet The Institute of Electrical and Electronic Engineers (IEEE) Basili Martínez Espinet IES Miquel Martí i Pol (Roda de Ter) bmartine@xtec.cat

En aquest treball pràctic es proposa el fenomen de la caiguda d'un imant de neodimi per un tub metàl-lic vertical (no ferromagnètic).També es proposa investigar com afecta el gruix del tub al temps de caiguda de l'imant; per a això fem servir un rotlle de paper d'alumini. Per mesurar el temps de caiguda podem fer servir sensors Hall i l'oscil.loscopi o bé un cronòmetre.

Paraules clau: corrent de Foulcault, corrents paràsits, efecte Hall, inducció

\section{Introducció}

Aquest treball pràctic té com a finalitat experimentar amb els corrents de Foucault i entendre el significat de les lleis de Faraday i de Lenz.

Per aconseguir aquest objectiu farem baixar un potent imant de neodimi per un tub metàl-lic conductor, però no ferromagnètic, que normalment és de coure o d'alumini. Llavors observarem el temps que triga per baixar.

Els corrents induïts que es generen s'oposen al moviment de caiguda de l'imant i el frenen ostensiblement (vegeu-ne aquests vídeos). El tub metàl-lic en el nostre cas serà un rotlle de paper d'alumini (Albal de $50 \mathrm{~m}$ ).

En aquesta pràctica es proposa investigar com afecta el gruix de l'alumini al temps de caiguda de l'imant.

Una de les moltes aplicacions pràctiques d'aquests corrents que també s'han anomenat "paràsits", és la del fre magnètic que s'utilitza en trens i vehicles pesants i és l'efecte que observem en aquesta pràctica.

\section{Fonaments teòrics}

El fenomen que observem és el moviment de caiguda d'un imant per un tub metàl-lic vertical. El tub i l'imant tenen forma cilíndrica. Al baixar l'imant pel tub varia el flux del camp magnètic i es produeixen corrents induïts, que s'anomenen corrents de
Foucault, d'Eddy, paràsits o tourbillionaires. La llei de Faraday - Lenz ens diu:

$$
\mathrm{V}(\mathrm{t})=\frac{-d \Phi}{d t}
$$

on $\mathrm{V}(\mathrm{t})$ és el voltatge del corrent induït, que es mesura en volts, i $\Phi$ és el flux magnètic, que es mesura en webers. El signe negatiu que apareix a la fórmula és l'aportació de Lenz que ens diu que el corrent induït s'oposa a la causa que el genera. El flux és igual al producte escalar del vector camp magnètic $B$ (que és el que proporciona l'imant i depèn del temps ja que s'està movent), per la superfície d'inducció $\mathrm{S}$.

El corrent que es genera en el tub d'alumini compleix que:

$$
\oint E \cdot d H=-\frac{d}{d t} \oint_{s} B \cdot d S
$$

Aquests corrents que s'oposen al moviment de caiguda de l'imant al final es dissipen en forma de calor.

Amb el nostre experiment comprovem que l'equació del moviment que es proposa a la bibliografia, aplicant la segona llei de Newton, té efectivament la forma:

$$
\mathrm{m} \frac{d v}{d t}=\mathrm{mg}-k v
$$

La força que s'oposa al pes de l'imant és proporcional a la velocitat de la seva caiguda; també s'ha determinat que la constant $k$ depèn del qua- 
drat del moment magnètic de l'imant i d'altres factors, com els diàmetres del tub i de l'imant, la conductivitat del metall i el gruix del tub (que és el factor que pretenem experimentar).

Aquesta pràctica també dóna peu a comentar la relació que hi ha entre la llei de Lenz i la llei de conservació de l'energia: en un moviment de caiguda lliure els corrents generats sempre s'oposen al moviment de caiguda, ja que si passés el contrari ens trobaríem que l'imant guanyaria energia i també podríem dissipar l'energia del corrent generat mitjançant una resistència. En realitat el que passa és que part de l'energia inicial de l'imant es transforma en energia elèctrica $i$ finalment en energia calorífica.

\section{Objectiu}

Veure quina influència té el gruix del tub metàl-lic en el temps de caiguda de l'imant.

\section{Material}

- Imant de neodimi de 2'5 cm x 0'9 cm

- Rotlle de paper Albal de 50 m

- Suport metàl-lic

- Cinta mètrica

- Cronòmetre

- Oscil-loscopi amb dos sensors Hall

- Font d'alimentació o bateria petita (12 V)

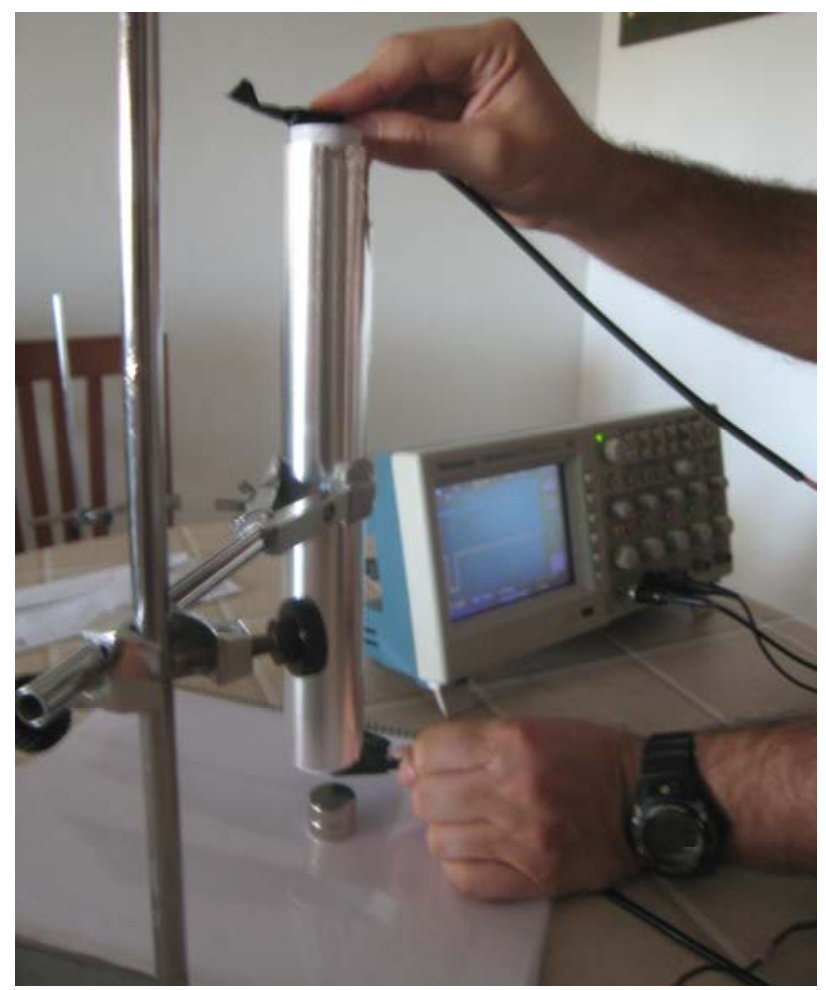

\section{Procediment experimental}

Muntem el rotlle de paper d'alumini en el suport metàl-lic mitjançant una pinça. Muntem els sensors Hall al punt de sortida i d'arribada de l'imant, els connectem a l'oscil-loscopi per mesurar el temps exacte de caiguda $\mathrm{i}$ al mateix temps a la font d'alimentació o a la bateria. A les fotos podem veure'n el muntatge.

Una altra opció, si no disposem de sensors Hall i oscil-loscopi, és mesurar el temps amb un cronòmetre, però llavors el temps obtingut no és tan exacte. Com podem veure a les fotos, els sensors Hall es poden aguantar amb les mans en el lloc on comença i on acaba l'alumini.

Deixem caure l'imant sense velocitat inicial i mesurem el temps que triga a baixar. Anem tallant fragments de $5 \mathrm{~m}$ del rotlle de paper d'alumini i anem mesurant de nou el temps de caiguda.

A les imatges podem veure el muntatge en detall. Cal una bateria o una font d'alimentació per connectar-hi els sensors Hall, sensors que també connectarem als canals 1 i 2 de l'oscil-loscopi.

\section{Dades i conclusions}

A la taula següent hi hem posat les dades que hem obtingut fent tres vegades l'experiment:

\begin{tabular}{|c|c|c|c|c|}
\hline $\begin{array}{l}\text { Longitud } \\
\text { alumini } \\
(\mathrm{m})\end{array}$ & $\begin{array}{c}\text { Temps } 1 \\
\text { (s) }\end{array}$ & $\begin{array}{c}\text { Temps } 2 \\
\text { (s) }\end{array}$ & $\begin{array}{c}\text { Temps } 3 \\
\text { (s) }\end{array}$ & $\begin{array}{c}\text { Mitjana } \\
\text { temps } \\
\text { (s) }\end{array}$ \\
\hline 45 & 3'54 & 3'46 & 3'46 & 3'49 \\
\hline 40 & 3'30 & 3'30 & 3'32 & 3'31 \\
\hline 35 & 3'10 & 3'06 & 3'06 & 3'07 \\
\hline 30 & 2'84 & $2 ' 82$ & $2 ' 80$ & 2'82 \\
\hline 25 & 2'56 & 2'56 & 2'56 & 2'56 \\
\hline 20 & 2'22 & $2^{\prime} 20$ & $2^{\prime} 20$ & 2'21 \\
\hline 15 & 1'77 & 1'80 & 1'81 & 1'79 \\
\hline 10 & 1'33 & 1'33 & 1'30 & 1'32 \\
\hline 5 & 0'76 & 0'77 & 0'77 & 0'77 \\
\hline 0 & 0'28 & 0'28 & 0'28 & 0'28 \\
\hline
\end{tabular}

A partir de les dades obtingudes podem fer la representació gràfica i intentar de veure quina relació hi ha entre les dues magnituds.

En el nostre cas, la gràfica obtinguda és la següent: 


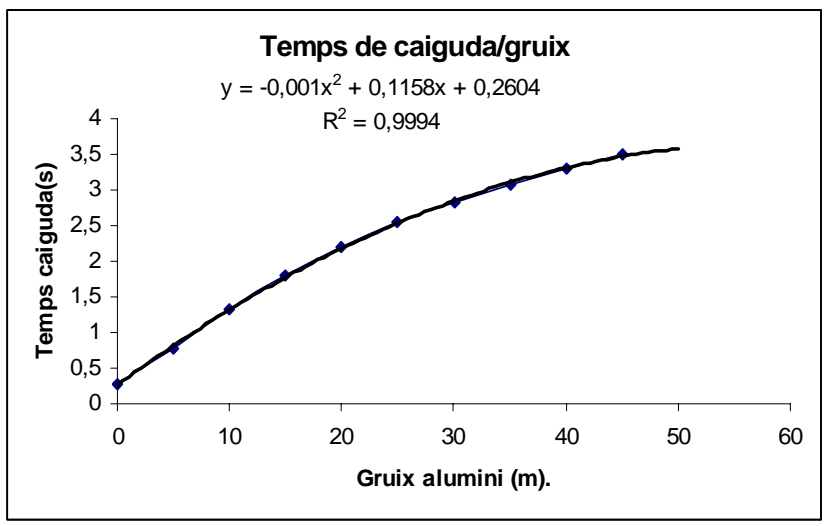

La gràfica s'aproxima relativament bé a una recta, però si ajustem les dades a un polinomi de segon grau l'ajust és gairebé perfecte: a la gràfica de més amunt podem veure com la corba ajustada se superposa molt ajustadament a la corba experimental. També hi podem observar que el terme de segon grau és molt petit i pesa poc en l'equació. Tot i així el coeficient de correlació és molt millor que si ajustem les dades a una recta.

El gruix de l'alumini expressat en metres es refereix a la llargada del paper d'alumini contingut en el rotlle. Hem suposat que a l'estar empaquetat a màquina el gruix real és proporcional a la seva llargada.

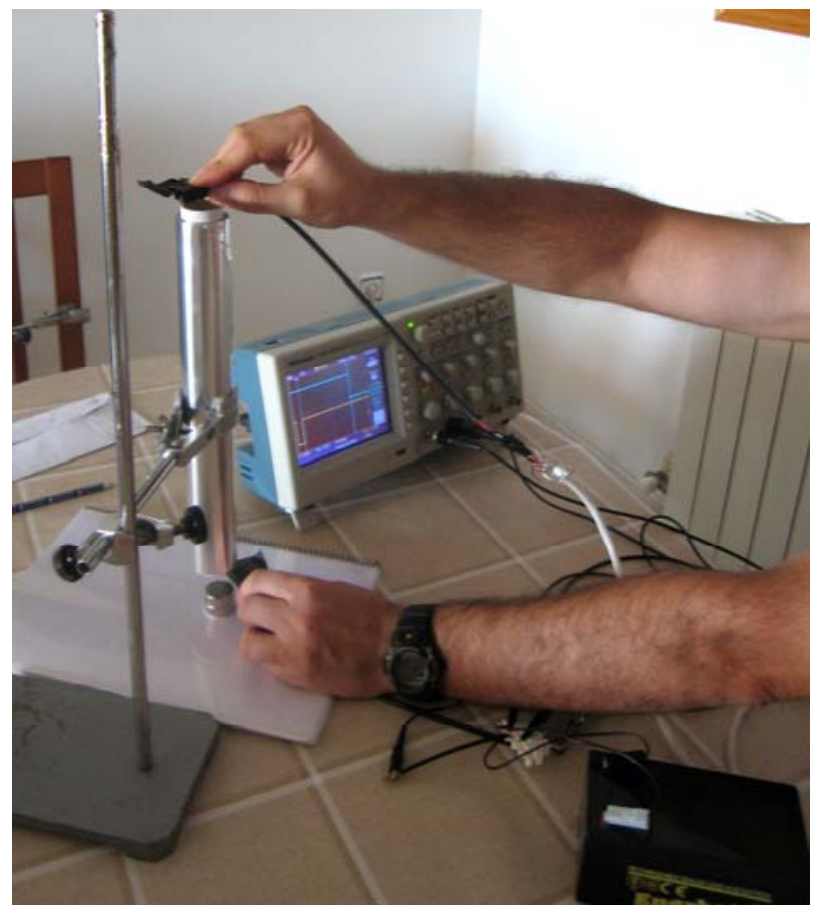

\section{Qüestions}

Finalment proposem unes quantes qüestions per millorar la comprensió de la pràctica.
1) Segons els resultats de la gràfica, quina relació hi ha entre el gruix i el temps de caiguda?

2) Creus que és important que l'alumini estigui molt ben empaquetat? Per què?

3) Si augmentéssim molt el gruix, creus que es podria frenar completament l'imant?

4) En què és transforma l'energia que perd l'imant en la seva frenada?

5) Creus que la conductivitat i la resistència del tub influeixen en l'experiment? Per què?

6) Si el tub fos d'un material superconductor, què creus que passaria? (Intenta contrastar la informació a la xarxa).

7) La temperatura del tub creus que hi pot tenir alguna influència?

8) En quins punts creus que es podria millorar la precisió de l'experiment?

9) Busca a la xarxa tres aplicacions dels corrents d'Eddy que consideris importants.

\section{Annex}

En aquesta part intentarem solucionar l'equació del moviment que es proposa a la bibliografia consultada.

L'equació del moviment que tenim aplicant la segona llei de Newton i les observacions experimentals és:

$$
\frac{d v}{d t} \mathrm{~m}=\mathrm{m} \mathrm{g}-\mathrm{k} \mathrm{v}
$$

on $m$ és la massa de l'imant $(\mathrm{kg}), g$ és la gravetat, $9,81 \mathrm{~m} / \mathrm{s}^{2}, v$ és la velocitat en $\mathrm{m} / \mathrm{s}$, i $k$ és una constant que depèn del gruix $i$ de la conductivitat del material, la relació de diàmetres entre l'imant i el tub, i del quadrat del moment magnètic de l'imant.

Si apliquem la transformada de Laplace a l'equació (1). Tenim:

$$
\begin{aligned}
& \mathrm{msv}=\frac{m g}{s}-\mathrm{kv} \\
& \mathrm{v}(\mathrm{m} \mathrm{s}+\mathrm{k})=\frac{m g}{\mathrm{~s}}
\end{aligned}
$$

per tant

$$
v(s)=\frac{m g}{s(m s+k)}=\frac{A}{s}+\frac{B}{(m s+k)}
$$


Si solucionem aquest sistema tindrem:

$$
A=\frac{m g}{k} \quad \text { i } \quad B=-m^{2} g / k
$$

Buscant la transformada inversa de Laplace, obtenim:

$$
\mathrm{v}(\mathrm{t})=\frac{m g}{k}\left(1-\mathrm{e}^{-\mathrm{kt} / \mathrm{m}}\right)
$$

que és doncs, la solució de l'equació. D'aquí veiem que $\mathrm{v}(0)=0$ i $\quad \mathrm{v}(\infty)=\mathrm{mg} / \mathrm{k}$.

Si representem gràficament la solució tindrem un gràfic semblant a aquest:

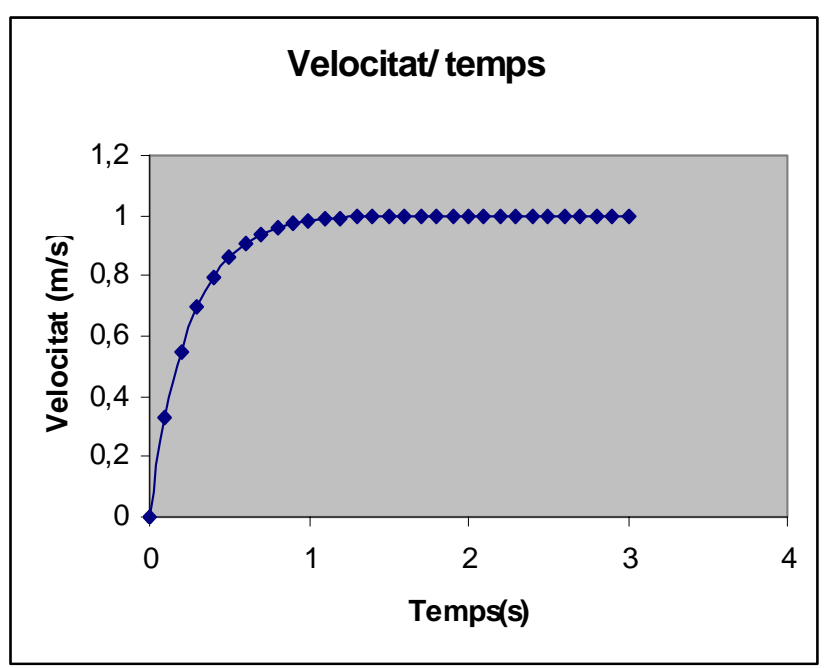

Els valors que hi hem donat no són reals, però ens permeten de veure que en aquest gràfic hi ha dues zones diferenciades:

-a la primera zona la velocitat augmenta en un interval de temps relativament curt

-a la segona zona la velocitat roman constant i adquireix el valor límit $m g / k$.
Hem fet una estimació del temps que es triga a assolir el valor límit per a un gruix corresponent a una llargada de 30 metres $i$ ens ha sortit que era de l'ordre dels mil.lisegons. Per tant, podem dir que la velocitat és essencialment constant en el temps.

\section{Bibliografia}

BILLO, E.J. (2007). Excel for scientists and enginers. Wiley-Interscience.

MOHAN, UNDELAND, ROBINS (1995). Power electronics. John Wiley \& Sons.

PURCELL, E.M. (1980). Electricidad y magnetismo. Editorial Reverté, 1980.

TIPLER, P.A. (1978). Física. Editorial Reverté.

\section{Webs d'interès}

http://corrienteseddy.tripod.com/

http://es.wikipedia.org/wiki/Corriente_de_Foucault http://www.jpimentel.com/ciencias_experimentales/ pagwebciencias/pagweb/Los_talleres_de_ciencias/electric http://www.fq.profes.net/archivo2.asp?id_contenido $=27981$

http://www.sc.ehu.es/sbweb/fisica/elecmagnet/indu ccion/foucault1/foucault1.htm

http://www.sc.ehu.es/sbweb/fisica/elecmagnet/indu ccion/foucault/foucault.htm

http://exa.unne.edu.ar/depar/areas/fisica/electymag ne/TEORIA/elecmagnet/induccion/foucault/fouc ault.htm

http://www.sc.ehu.es/sbweb/fisica_lelecmagnet/fara day/foucault1/foucault__lab.html 